\title{
Primary Effusion Lymphoma
}

National Cancer Institute

\section{Source}

National Cancer Institute. Primary Effusion Lymphoma. NCI Thesaurus. Code C6915.

A large B-cell lymphoma usually presenting as a serous effusion without detectable tumor masses. It is universally associated with human herpes virus 8 (HHV8), also called Kaposi sarcoma-associated herpesvirus. It mostly occurs in the setting of immunodeficiency. The most common sites of involvement are the pleural, pericardial, and peritoneal cavities. Rare HHV8-positive lymphomas indisting uishable from primary effusion lymphomas (PEL) present as solid tumor masses, and have been termed extracavitary PEL. The prognosis is extremely unfavorable. (WHO 2017) 